\title{
Use of Research Evidence in Policy and Decision-Making: Views, Attitudes and Practices of Health Policy Makers in Lusaka Province of Zambia
}

\author{
Patricia Katowa-Mukwato ${ }^{1}$, Lonia Mwape ${ }^{2}$, Mwaba Chileshe Siwale1, \\ Emmanuel Mwila Musenge1, Margaret Maimbolwa ${ }^{3}$
}

\author{
${ }^{1}$ Department of Basic and Clinical Nursing Sciences, School of Nursing Sciences, University of Zambia, Lusaka, Zambia \\ ${ }^{2}$ Department of Mental Health and Psychiatric Nursing, School of Nursing Sciences, University of Zambia, Ridgeway Campus, \\ Lusaka, Zambia \\ ${ }^{3}$ Department of Midwifery, Women and Child Health, School of Nursing Sciences, University of Zambia, Lusaka, Zambia \\ Email: * patriciakatowamukwato@gmail.com
}

How to cite this paper: Katowa-Mukwato, P., Mwape, L., Siwale, M.C., Musenge, E.M. and Maimbolwa, M. (2018) Use of Research Evidence in Policy and Decision-Making: Views, Attitudes and Practices of Health Policy Makers in Lusaka Province of Zambia. Health, 10, 502-515.

https://doi.org/10.4236/health.2018.104040

Received: March 12, 2018

Accepted: April 27, 2018

Published: April 30, 2018

Copyright (c) 2018 by authors and Scientific Research Publishing Inc. This work is licensed under the Creative Commons Attribution International License (CC BY 4.0).

http://creativecommons.org/licenses/by/4.0/

c. (i) Open Access

\begin{abstract}
Background: The integration of relevant high-quality research evidence into the health decision and policy formulation process is a key strategy for improving health systems especially in developing countries such as Zambia. However, the lack of capacity to understand and value research evidence by policy and decision makers makes it difficult for them to find and use research evidence in a timely manner even when motivated to do so. This study aimed to establish the views, attitudes and practices of policy makers on the use of research evidence in policy and decision-making process in Zambia. Methodology: This descriptive cross-sectional study was conducted in Lusaka, Zambia among selected public health decision and policy making institutions. A purposive sample of 21 consenting policy makers who were working in different positions in the Ministry of Health Headquarters, Provincial and District Health Offices, Health Professions Regulatory Bodies, United Nations Agencies, International Non-Governmental Organizations and University Deans from the University of Zambia participated in the study. A self-administered questionnaire was used to collect data. The $\mathrm{IBM}^{\circledR}{ }^{\circledR}$ SPSS ${ }^{\star}$ Statistics for Windows Version 20.0 was used for data analysis. Results: The concept of Evidence Informed Health Policy was not well understood such that only less than half (47.5\%) of the participants reported having heard specifically about Evidence Informed Health Policy meanwhile almost two thirds (61.9\%) reported that they used research evidence in decision making and
\end{abstract}


policy formulation. Similar discrepancy was expressed in the understanding of and use of rapid response mechanisms such that although (47.6\%) of the participants reported having heard about it, (57\%) had never used rapid response mechanisms for decision-making. With regard to the sources of information, about half (52.3) of the participants reported scholarly articles as their main source of evidence. Conclusion and Recommendations: There is need for more sensitization and capacity building among the decision and policy makers on the importance of using research evidence in decision and policy making process as incorporation of relevant high-quality research evidence into the health policy making process is a key strategy for improving health systems.

\section{Keywords}

Evidence-Informed Health Policy, Rapid Response Mechanisms, Decision-Making

\section{Introduction}

Evidence-informed health policymaking is an approach to policy decisions that is intended to ensure that decision-making is well-informed by the best available research evidence [1]. Literature asserts that evidence from research can improve the health policy process, by identifying new issues for the policy agenda, informing decisions about policy content and direction, and evaluating the impact of policy [2]. Similarly, World Health Organization [3] recognizes that strong and effective health systems that are evidence-based in their operations are vital to achieve continued improvement in health outcomes in an efficient and equitable manner. Further literature affirms that the integration of relevant high-quality research evidence into the health decision and policy formulation process is a key strategy for improving health systems worldwide [4] [5]. In view of the importance of evidence in developing effective policies, health policy makers should be aware of the need to base their decision-making and policy formulation on best available evidence.

Despite the documented significance of research evidence in developing health policies that have potential for promoting health, researchers have documented poor or inadequate use of research evidence citing numerous barriers including: decision makers' perceptions of research evidence; the gulf between researchers and decision makers; the culture of decision-making; competing influences on decision-making; and practical constraints [6]. On the other hand Dawad and Veenstra [7] noted some internal barriers to use of research evidence and asserted that without adequate capacity, in knowledge translation/management and health policy research, policymakers will not have the capacity to access and synthesize sound information on which to base decisions. Additional barriers revealed by other researchers include practical constraints such as incompatible 
timeframes for research and policy making [8] [9], problems in disseminating and accessing research evidence [8] [10] and in its presentation (which was seen to be aimed at an academic audience) leaving out policy makers who are supposed to be consumers of research evidence.

As a means to overcoming the barrier to the uptake of research evidence by policy makers, some strategies have been suggested including promotion of effective interaction between researchers and policymakers [11] and conducting research targeted at the needs of decision makers, research clearly highlighting key messages, and capacity building in the area of knowledge translation [6]. In addition, correct packaging of research evidence is important as policy makers prefer to have information in a brief format so that they can review it quickly and if relevant, they consider more information [8]. With this background, our study evaluated the views, attitudes and practices of health policy makers towards the use of research evidence in policy and decision-making with a view to identify barrier and facilitators of the use of research evidence among policy makers from the Zambian context. This was a baseline survey conducted, prior to the implementation of the "Using Evidence to Strengthen Health Systems in East Central and Southern Africa (ECSA) and Middle East and Northern" (MENA) (US Evidence project) Project number 107498-003.

\section{Methods}

\subsection{Study Design and Sampling Procedures}

A descriptive cross-sectional survey design was used to collect data on views, attitudes and practices of policy makers on the use of research evidence in decision-making. The study was conducted in the Lusaka Province of Zambia targeting policy makers who had worked for at least for six months in different policy making positions in the Ministry of Health Headquarters, Provincial and District Health Offices, Health Professions Regulatory Bodies, United Nations Agencies, International Non-Governmental Organizations and University Deans from the University of Zambia. Institutions were purposively selected based on the researchers' prior knowledge of both governmental and non-governmental institutions involved in health policy making within the Lusaka Province of Zambia, which is the country's capital city. Therefore a total of 12 institutions with at least three policy makers per institution were contacted to participate in the study. Out of the targeted population of 36,21 policy makers consented, answered and returned the questionnaire.

\subsection{Data Collection and Analysis}

Data were collected using a self-administered questionnaire which comprised both closed and open ended questions, resulting into quantitative and qualitative data sets. For this article, only the quantitative component is reported while the qualitative was reported in a different manuscript. The participant completed the questionnaire within their offices or work environment. The data were col- 
lected in February 2017. The IBM $^{\circledR}$ SPSS ${ }^{\circledR}$ Statistics for Windows Version 20.0 (IBM Corp. Armonk, NY, USA) was used to summarise the quantitative data with consequent generation of frequencies and proportions.

\subsection{Ethical Approval}

This study was approved by the ERES Converge (Assurance No. F. W. A. 00011697, I. R. B. No. 00005948) with Ref. No. 2013-Dec-005.

\section{Results}

\subsection{Demographic Characteristics of the Participants}

The distributions of participant's demographic characteristics are shown in Table 1.

Table 1 shows that 11 (52.4\%) of the participants were aged between 40 - 49 years old and $13(61.9 \%)$ were females. Nineteen $(90.5 \%)$ of the participants held university degrees and 2 (9.5\%) had college diplomas. Seventeen (81\%) had a medical background and 15 (71.4\%) had been qualified for more than 10 years. The participants held different portfolios, all of which entailed involvement in decision or policy-making. Nineteen $(90.5 \%)$ had held their positions for less than 10years. Fourteen (66.6\%) of the participants held the position of program officer at both regulatory and non-regulatory bodies. Of the total participants, 11 (52.4\%) viewed themselves as decision makers and $1(4.8 \%)$ as neither a decision maker nor an adviser.

\subsection{Views, Attitude and Practice of Evidence-Informed Health Policy}

The proportions of participant's views, attitude and practice of evidence-informed health policy (EIHP) are shown in Tables 2-5.

Table 2 shows that, when asked if they have heard about EIHP, 11 (52.4\%) of the participants indicated that had not while the remaining $10(47.6 \%)$ stated that they had. Surprisingly, 17 (81.0\%) of the participants reported that EIHP is very important and only $1(4.8 \%)$ reported that it is very unimportant.

Table 3 shows that 13 (61.9\%) of the participants reported that it was very important to use research evidence in health system policies and only $1(4.8 \%)$ reported that it was very unimportant. 10 of the participants (47.6\%) indicated that it was very important to have health system policies informed by research evidence. With regard to use of evidence in decision-making, 11 (52.4\%) of the participants use evidence sometimes while $6(28.6 \%)$ used evidence all the time when making decisions. Only $3(14.3 \%)$ of the participants said that it was extremely easy to use research evidence in policy and decision-making in urgent situations while 7 (33.3\%) stated that it was difficulty. Nevertheless, 12 (57.1\%) of the participants indicated that it was valuable to use research evidence in decision-making. When asked on the frequency of use of RRM, 14 (66.7\%) of the participants reported often and only 1 (4.8\%) reported occasionally. With regard 
Table 1. Demographic characteristics of the participants.

\begin{tabular}{|c|c|c|}
\hline Characteristic/Variable & Frequency & Percent \\
\hline \multicolumn{3}{|l|}{ Age of participant } \\
\hline $30-39$ years & 5 & 23.8 \\
\hline $40-49$ years & 11 & 52.4 \\
\hline $50-59$ years & 5 & 23.8 \\
\hline Total & 21 & 100 \\
\hline \multicolumn{3}{|l|}{ Gender of participant } \\
\hline Male & 7 & 33.3 \\
\hline Female & 13 & 61.9 \\
\hline No answer & 1 & 4.8 \\
\hline Total & 21 & 100 \\
\hline \multicolumn{3}{|l|}{ Qualification of participant } \\
\hline Diploma & 2 & 9.5 \\
\hline Bachelor of science or art & 8 & 38.1 \\
\hline Master's degree & 8 & 38.1 \\
\hline Doctorate & 3 & 14.3 \\
\hline Total & 21 & 100 \\
\hline \multicolumn{3}{|l|}{ Educational background } \\
\hline Medical & 17 & 81.0 \\
\hline Non-medical & 4 & 19.0 \\
\hline Total & 21 & 100 \\
\hline \multicolumn{3}{|l|}{ Duration of service } \\
\hline$\leq 10$ years & 5 & 23.8 \\
\hline $11-20$ years & 6 & 28.6 \\
\hline $21-30$ years & 6 & 28.6 \\
\hline $31-40$ years & 3 & 14.3 \\
\hline No answer & 1 & 4.8 \\
\hline Total & 21 & 100 \\
\hline \multicolumn{3}{|l|}{ Position at current organization } \\
\hline Nursing officer & 4 & 19.0 \\
\hline Epidemiologist/Researcher & 2 & 9.5 \\
\hline Program officer/Regulatory body & 8 & 38.1 \\
\hline Program officer/Non-regulatory body & 6 & 28.6 \\
\hline Dean/University & 1 & 4.8 \\
\hline Total & 21 & 100 \\
\hline \multicolumn{3}{|l|}{ Duration on current position } \\
\hline$\leq 10$ years & 19 & 90.5 \\
\hline $10-25$ years & 2 & 9.5 \\
\hline Total & 21 & 100 \\
\hline \multicolumn{3}{|l|}{ How participants view themselves } \\
\hline Decision maker & 11 & 52.4 \\
\hline Advisor & 9 & 42.9 \\
\hline No response & 1 & 4.8 \\
\hline Total & 21 & 100 \\
\hline
\end{tabular}


Table 2. Participants view of evidence-informed health policy.

\begin{tabular}{ccc}
\hline Characteristic/Variable & Frequency & Percent \\
\hline $\begin{array}{c}\text { Hearing of rapid Response Mechanisms in } \\
\text { Evidence-Informed Health Policy }\end{array}$ & & \\
No & 11 & 52.4 \\
Yes & 10 & 47.6 \\
Total & 21 & 100 \\
Importance of Evidence-Informed Health Policy & & \\
Very unimportant & 1 & 4.8 \\
Unimportant & 0 & 0.0 \\
Neither important nor important & 0 & 0.0 \\
Important & 3 & 14.3 \\
Very Important & 17 & 81.0 \\
Total & 21 & 100 \\
\hline
\end{tabular}

Table 3. Attitudes of participants towards evidence-informed health policy.

\begin{tabular}{|c|c|c|}
\hline Characteristic/Variable & Frequency & Percent \\
\hline \multicolumn{3}{|c|}{$\begin{array}{l}\text { Importance of health system policies and } \\
\text { decisions being informed by research evidence }\end{array}$} \\
\hline Very unimportant & 1 & 4.8 \\
\hline Unimportant & 0 & 0.0 \\
\hline Neither important nor important & 1 & 4.8 \\
\hline Important & 6 & 28.6 \\
\hline Very Important & 13 & 61.9 \\
\hline Total & 21 & 100 \\
\hline \multicolumn{3}{|c|}{$\begin{array}{l}\text { Importance of health system policies and decisions being } \\
\text { informed by research evidence in urgent situations }\end{array}$} \\
\hline No answer & 1 & 4.8 \\
\hline Very unimportant & 0 & 0.0 \\
\hline Unimportant & 0 & 0.0 \\
\hline Neither important nor important & 2 & 9.5 \\
\hline Important & 8 & 38.1 \\
\hline Very important & 10 & 47.6 \\
\hline Total & 21 & 100 \\
\hline \multicolumn{3}{|c|}{$\begin{array}{l}\text { Expectation to use research evidence in policy and } \\
\text { decision-making in urgent situations }\end{array}$} \\
\hline No answer & 0 & 0.0 \\
\hline Never & 1 & 4.8 \\
\hline Rarely & 1 & 4.8 \\
\hline Occasionally & 1 & 4.8 \\
\hline Sometimes & 11 & 52.4 \\
\hline All time & 6 & 28.6 \\
\hline Total & 21 & 100 \\
\hline
\end{tabular}




\section{Continued}

Difficulty of using research evidence in policy and decision-making in urgent situations

Extremely difficult $\quad 0 \quad 0.0$

Difficult

Neither easy nor difficult

$$
\text { Easy }
$$

Extremely easy

Total

Value of using research evidence in policy and decision-making in urgent situations

$$
\begin{gathered}
\text { Extremely of no value } \\
\text { Of no value }
\end{gathered}
$$

Neither valuable nor of no value

$$
\text { Valuable }
$$

Extremely valuable

Total

Value of a service that could help participant to access research about health systems quickly when needed

$$
\begin{aligned}
& \text { No answer } \\
& \text { Very valuable } \\
& \text { No valuable }
\end{aligned}
$$

Neither valuable nor invaluable

Valuable

Very valuable

Total

Frequency of using rapid response mechanism

No answer
Never
Rarely
Occasionally
Often

All the time

Total

Rapid response mechanism promotion amongst peers

No answer
Strongly disagree

Disagree

Neither agree nor disagree

Agree

Strongly agree

Total
4.8 
to the promotion of RRM among peers, 10 (47.6\%) of the participants strongly agreed, 7 (33.3\%) agreed to promoting use of evidence among peers, while (14.3\%) neither agreed nor disagreed.

Table 4 reveals that, 8 (38.1\%) of the participants frequently needed evidence urgently within hours or days and only 1 (4.8\%) of the participants rarely needed evidence. when asked about the helpfulness of the methods used as sources of research evidence, $11(52.4 \%)$ of the participants stated that the methods were helpful, similarly, 9 (42.9\%) stated that the methods were very helpful. On the challenges with the methods mentioned, 9 (42.9\%) and another 9 (42.9\%) of the participants reported occasionally and often respectively.

Table 4. Participants practice of evidence-informed health policy.

\begin{tabular}{|c|c|c|}
\hline Characteristic/Variable & Frequency & Percent \\
\hline \multicolumn{3}{|l|}{$\begin{array}{l}\text { Frequency in the need of rapid evidence } \\
\text { within hours or days }\end{array}$} \\
\hline No answer & 1 & 4.8 \\
\hline Never & 0 & 0.0 \\
\hline Rarely & 1 & 4.8 \\
\hline Occasionally & 6 & 28.6 \\
\hline Often & 5 & 23.8 \\
\hline All the time & 8 & 38.1 \\
\hline Total & 21 & 100 \\
\hline \multicolumn{3}{|l|}{ Sources of research evidence } \\
\hline Scholarly articles & 11 & 52.3 \\
\hline Reports on policy and guidelines & 4 & 19.0 \\
\hline Research reports & 4 & 19.0 \\
\hline No response & 2 & 9.5 \\
\hline Others (conferences, seminars etc.) & 0 & 0 \\
\hline Total & 21 & 100 \\
\hline \multicolumn{3}{|c|}{ Helpfulness of sources of research evidence } \\
\hline No answer & 1 & 4.8 \\
\hline Very unhelpful & 0 & 0.0 \\
\hline Unhelpful & 0 & 0.0 \\
\hline Neither helpful nor unhelpful & 0 & 0.0 \\
\hline Helpful & 11 & 52.4 \\
\hline Very helpful & 9 & 42.9 \\
\hline Total & 21 & 100 \\
\hline \multicolumn{3}{|l|}{ Challenges with the method(s) mentioned } \\
\hline Never & 0 & 0.0 \\
\hline Rarely & 1 & 4.8 \\
\hline Occasionally & 9 & 42.9 \\
\hline Often & 9 & 42.9 \\
\hline All the time & 1 & 4.8 \\
\hline No answer & 1 & 4.8 \\
\hline Total & 21 & 100 \\
\hline
\end{tabular}


Table 5. Capacity of participants to use rapid response mechanisms.

\begin{tabular}{ccc}
\hline Characteristic/Variable & Frequency & Percent \\
\hline $\begin{array}{c}\text { Capacity to use a rapid } \\
\text { response mechanism }\end{array}$ & 12 & \\
Never & 1 & 57.1 \\
Rarely & 4 & 4.8 \\
Occasionally & 3 & 19.0 \\
Often & 1 & 14.3 \\
All the time & 21 & 4.8 \\
Total & & 100 \\
\hline
\end{tabular}

Table 5 shows that $12(57.1 \%)$ of the participants had never used the RRM and only $1(4.8 \%)$ use the RRM all the time.

\section{Discussion}

In the African context including Zambia, research evidence is 'not absent', but understanding of what constitute research evidence tends to vary considerably [12]. The depth and quality of knowledge used by policy makers influence the effectiveness of policies. There is a shortage of evidence on policy makers' actual capacity to use research evidence and there is even less evidence on effective strategies to build their capacity. Highlighting gaps in the current understanding of EIHP among the decision makers in Zambia was thought to be critical.

This article presents discussion of findings from twenty-one policy makers which were obtained using a semi structured interview schedule. A total of 21 participants took part in the study where a self-administered semi structured questionnaire was used. Almost all of the participants were programme officers from either regulatory or non-regulatory government institutions 14 (66, 7\%) (Table 1). Eleven (11) had a minimum of a Master's degree (Table 1). Higher level Qualifications place the policy makers at an advantage to understand research and to be able to utilize it for health policy decision and formulation. The World Health Organization [13], emphases the use of research evidence when developing health policies. Literature alerts us that EIHP helps in saving lives through having more effective health policies that respond to scientific and technological advances and effective use of resources consequently improving health systems worldwide [4] [5]. Therefore, having well qualified policy makers was important as shown in a review of local and global practices of evidence informed health policy conducted by Tilahun and colleagues [14]. Tilahun and colleagues [14], asserted that policy makers needed to have political and policy making skills and should be able to understand research, to that effect the Minister of Health in Rwanda worked towards ensuring that all staff members had a minimum of a master's degree.

In the current study as shown in Table 1, seventeen (17) participants had a 
medical background while 16 (76\%) had been working for more than 10 years indicating that they had gained some experience in their positions. This is important as it promotes retention of historical knowledge capable of leading policy development and review process of policies [14]. Although they held high positions in these institutions they had different views of their roles such that when they were asked on how they viewed themselves eleven out of the twenty-one viewed themselves as decisional makers while nine reported that they viewed themselves as advisors (Table 1). Studies conducted by Talihun et al. and Brownson [14] [15] indicated that leadership among policy makers was critical to prevent political and economic interests that may derail evidence use in health policy. In order to evaluate their understanding of the value for EIHP, participants were asked to indicate its value with regard to their work, 17 (81\%) (Table 2 ) indicated that use of evidence in policy making was very important. With literature pointing to the fact that inadequate knowledge and poor perception of knowledge translation/management and health policy research, policymakers will not have the capacity to access and synthesize sound information on which to base decisions [7], it can therefore be assumed that the policy makers who participated in this study will utilize research evidence in the event that they had no other barriers.

This study further investigated the attitude of participants towards EIHP in Zambia. The study revealed that most of the participants considered use of research evidence in health system policies to be very important 13 (61.9\%) (Table 3). Surprisingly, despite the reported importance of EIHP, majority of the participants in this study, used evidence only sometimes with only a few who used evidence all the time when making decisions. Similarly, Mijumbi and colleagues [16] reported that, all the policymakers affirmed that research evidence was an important part of the policymaking process. This confirms the important of using research evidence in the decision-making process.

Further, when the participants were asked about their practice towards EIHP, our study revealed that out of the 21 participant, 5 (23.5) and 8 (38.1\%) either often or all the times needed evidence for decision-making either within hours or days (Table 4). With regard to the sources of evidence, majority of the participants reported scholarly articles as their source of evidence and a few from research reports. When asked about the helpfulness of the methods used as sources of research evidence, majority $20(94.2 \%)$ of the participants stated that the methods were either helpful or very helpful (Table 4). On the challenges with the methods used to source evidence, almost all had challenges with the sources of evidence (Table 4).

According to Orton et al. (2011), there is little reliable evidence quantifying the extent to which research evidence is used in public health decision-making processes. On the sources of evidence for the health policy makers researchers [17] [18] reported use of systematic review, while El-Jardali and others [19] and Dobbins, Cockerill and Barnsley [18] reported use of academic research. In addition, Dobbins, Cockerill and Barnsley [18] reported provincial health, recreation 
organisations; non-government, voluntary organisations; and list serves as sources of evidence. The reviews ware perceived to be easy to use as they overcame the barrier of limited critical appraisal skills.

Contrary to our findings where the mostly utilized source of evidence were scholarly articles, according to Ritter [20], the most frequent sources of evidence was seeking advice from an expert and consulting technical reports. Also, accessing the internet, using statistical data and consulting policy makers in other jurisdictions were used in about half the cases. The least frequently used sources were academic literature, relying on internal expertise, policy documents and employing a consultant. There is need for researchers to consider the sources of evidence that the policy makers use if they wish their research to be utilised in the policy making process. In addition, Ritter [20] reported that research is only one of several sources of information drawn upon when making decisions. It's important to understand that, the influence of key personnel is a very big factor in the decision-making process. The influential personnel make decisions based on either common sense or expert opinion or by acting as a filter through which evidence is transferred. Thus, a collaborative effort of all the major players in the decision-making process should be considered especially that research evidence is only seen to affect policy with the support and commitment of those who had influence for change [19].

Although most participants in our study reported that evidence was helpful in making decisions, there are factors that can affect its use. Some of the factors reported by previous research [6] are; the perceived lack of research evidence among public health decision makers, the gulf between decision makers and researchers, prevented the production of research from feeding into the decision-making processes. In addition Wallace, Nwosu and Clarke [21] reported that, majority of the participants did not use evidence in decision-making due to lack of awareness, lack of access, lack of familiarity, lack of usefulness, and lack of motivation. Knowing that most participants did not use evidence in decision-making is an eye opener to considering capacity in RRM among the policy and decision makers.

Furthermore, this study showed that, majority of the participants had never used the RRM and only one had used the RRM all the time (Table 5). Similarly, researcher like Lavis and colleagues [8] reported that policy makers were not supported to acquire the required skills or to use research evidence in different forms. In addition, Mijumbi and others [16] indicated a lack of experience in RRM among policy makers and thus addressing this problem through such mechanisms and if accepted by policymakers can go a long way in improving capacity of policy makers in using RRM services. Thus, capacity building is also seen as important to increase researchers' abilities to produce and effectively disseminate evidence of use to decision makers [10] and to improve policy makers' abilities to critically appraise and interpret these outputs [17]. This is compounded by the fact that evidence on how to overcome these barriers to the use 
of research evidence in public health decision-making is less extensive. But there is need for improved communication and sustained dialogue between researchers and end users of research. Policy makers can be oriented on how to use research evidence especially systematic reviews as they effectively summarise evidence and increase confidence through critical appraisal [18]. There is also need to change the culture within which policy makers work such as structures, rewards and training so that more value is placed on the use of research evidence for decisions as this might encourage its use [6].

\section{Limitations of the Study}

The results of our study might have been affected by limited sample size, with eventual failure to model the results. This small sample size is attributed to the reluctance by the policy makers to supply data through questionnaires despite the tool being delivered administered to them. Thus, making it difficult to establish a clear picture of the views, attitude and practice of policy makers on EIHP in Zambia. In addition, since the study was cross-section and sampling convenient, it is not possible to establish a "causal" relation among views, attitude and practice of EIHP.

\section{Conclusion}

Most of the participants reported that EIHP is very important in the decision-making process, although less than half of the participants reported having heard about EIHP. In addition, less than half of the participants reported that they frequently needed evidence urgently within hours or days during their decision-making process. More than half of the participants reported scholarly articles as their main source of evidence and did not have serious challenges with their sources of research evidence. However, more than half of the participants had never used the RRM and only one participant used the RRM all the time. There is thus need for more sensitization among the policy makers on EIHP and its importance and at the same time build capacity so as to enhance utilization of research evidence in the decision-making process and policy formulation.

\section{Competing Interests}

The authors declare that they have no competing interests in the study.

\section{Author's Contributions}

All the authors contributed equally, read and approved the final manuscript.

\section{Acknowledgements}

We are sincerely grateful to the International Development Research Centre (IDRC) of Canada for funding the "Using Evidence to Strengthen Health Systems in East Central and Southern Africa (ECSA) and Middle East and Northern (MENA) (Us Evidence project) Project number 107498-003. We are also grate- 
ful to all the policy makers who participated in the study.

\section{References}

[1] Oxman, A.D., Lavis, J.N., Lewis, S. and Fretheim, A. (2009) SUPPORT Tools for Evidence-Informed Health Policymaking (STP) 1: What Is Evidence-Informed Policymaking? Health Research Policy and Systems, 7, S1. https://doi.org/10.1186/1478-4505-7-S1-S1

[2] Campbell, D.M., Redman, S., Jorm, L., Cooke, M., Zwi, A.B. and Rychetnik, L. (2009) Increasing the Use of Evidence in Health Policy: Practice and Views of Policy Makers and Researchers. Australia and New Zealand Health Policy, 6, 21. https://doi.org/10.1186/1743-8462-6-21

[3] World Health Organization (2008) Report on Meeting on Health Systems Strengthening and Primary Health Care. Report Series No RS/2008/GE/35(PHL). Regional Office for the Western Pacific Manila, Philippines.

[4] Lavis, J.N., Posada, F.B., Haines, A. and Osei, E. (2004) Use of Research to Inform Public Policy Making. Lancet, 364, 1615-1621.

https://doi.org/10.1016/S0140-6736(04)17317-0

[5] Moat, K.A. and Lavis, J.N. (2012) 10 Best Resources for Evidence-Informed Health Policymaking. Health Policy Planning, 1, 4.

[6] Orton, L., Lloyd-Williams, F., Taylor-Robinson, D., O’Flaherty, M. and Cape Well, S. (2011) The Use of Research Evidence in Public Health Decision Making Processes: Systematic Review. PLOS ONE, 6, e21704.

https://doi.org/10.1371/journal.pone.0021704

[7] Dawad, S. and Veenstra, N. (2007) Comparative Health Systems Research in a Context of HIV/AIDS: Lessons from a Multi-Country Study in South Africa, Tanzania and Zambia. Health Research Policy and Systems, 5, 13. https://doi.org/10.1186/1478-4505-5-13

[8] Lavis, J., Davies, H., Oxman, A., Denis, J.L., Golden-Biddle, K., et al. (2005) Towards Systematic Reviews That Inform Health Care Management and Policy-Making. Journal of Health Services Research \& Policy, 10, 35-48. https://doi.org/10.1258/1355819054308549

[9] Bickford, J.J. and Kothari, A.R. (2008) Research and Knowledge in Ontario Tobacco Control Networks. Canadian Journal of Public Health, 99, 297-300.

[10] Kiefer, L., Frank, J., Di Ruggiero, E., Dobbins, M. and Manuel, D. (2005) Fostering Evidence-Based Decision-Making in Canada-Examining the Need for a Canadian Population and Public Health Evidence Centre and Research Network. Canadian Journal of Public Health, 96, I1-I19.

[11] Innvaer, S., Vist, G., Trommald, M. and Oxman, A. (2002) Health Policy-Makers' Perceptions of Their Use of Evidence: A Systematic Review. Journal of Health Services Research \& Policy, 7, 239-244. https://doi.org/10.1258/135581902320432778

[12] Broadbent, E. (2012) Policy Debates and Research-Based Evidence in Africa: So What, and What Now? International Evidence-Informed Policy Making Conference, Ile-Ife, 27-29 February 2012.

[13] World Health Organization (2004) World Report on Knowledge for Better Health: Strengthening Health Systems. Geneva.

[14] Tilahun, H., Flannery, J. and Berman, P. (2015) Review of Local and Global Practices on Evidence-Informed Health Policy: Recommendations for Ethiopia. Harvard T.H. Chan School of Public Health, Boston. 
[15] Brownson, R.C., Chriqui, J.F. and Stamatakis, K.A. (2009) Understanding Evidence-Based Public Health Policy. American Journal of Public Health, 99, 1576-1583. https://doi.org/10.2105/AJPH.2008.156224

[16] Mijumbi, R.M., Oxman, A.D., Panisset, U. and Sewankambo, N.K. (2014) Feasibility of a Rapid Response Mechanism to Meet Policymakers' Urgent Needs for Research Evidence about Health Systems in a Low Income Country: A Case Study. Implement Science, 9, 114. https://doi.org/10.1186/s13012-014-0114-z

[17] Asthana, S. and Halliday, J. (2006) Developing an Evidence Base for Policies and Interventions to Address Health Inequalities: The Analysis of "Public Health Regimes”. Milbank Q, 84, 577-603. https://doi.org/10.1111/j.1468-0009.2006.00459.x

[18] Dobbins, M., Cockerill, R. and Barnsley, J. (2001) Factors Affecting the Utilization of Systematic Reviews-A Study of Public Health Decision Makers. International Journal of Technology Assessment in Health Care, 17, 203-214. https://doi.org/10.1017/S0266462300105069

[19] El-Jardali, F., Lavis, J.N., Ataya, N. and Jamal, D. (2012) Use of Health Systems and Policy Research Evidence in the Health Policymaking in Eastern Mediterranean Countries: Views and Practices of Researchers. Implementation Science, 7, 2. https://doi.org/10.1186/1748-5908-7-2

[20] Ritter, A. (2009) How Do Drug Policy Makers Access Research Evidence? International Journal of Drug Policy, 20, 70-75. https://doi.org/10.1016/j.drugpo.2007.11.017

[21] Wallace, J., Nwosu, B. and Clarke, M. (2012) Barriers to the Uptake of Evidence from Systematic Reviews and Meta-Analyses: A Systematic Review of Decision Makers' Perceptions. BMJ Open, 2, e001220. 